\title{
Waterproof coatings for high-power laser cavities
}

\author{
Xinbin Cheng $\mathbb{1}^{1,2,3}$, Siyu Dong ${ }^{1,2}$, Song Zhi ${ }^{1,2}$, Sebastian Paschel ${ }^{4}$, Istvan Balasa ${ }^{4}$, Detlev Ristau ${ }^{4}$ and \\ Zhanshan Wang ${ }^{1,2,3}$
}

\begin{abstract}
With the ever-increasing laser power and repetition rate, thermal control of laser media is becoming increasingly important. Except for widely used air cooling or a bonded heat sink, water cooling of a laser medium is more effective in removing waste heat. However, how to protect deliquescent laser media from water erosion is a challenging issue. Here, novel waterproof coatings were proposed to shield Nd:Glass from water erosion. After clarifying the dependence of the waterproof property of single layers on their microstructures and pore characteristics, nanocomposites that dope $\mathrm{SiO}_{2}$ in $\mathrm{HfO}_{2}$ were synthesized using an ion-assisted co-evaporation process to solve the issue of a lack of a highindex material that simultaneously has a dense amorphous microstructure and wide bandgap. $\mathrm{Hf}_{0.7} \mathrm{Si}_{0.3} \mathrm{O}_{2} / \mathrm{SiO}_{2}$ multifunctional coatings were finally shown to possess an excellent waterproof property, high laser-induced damage threshold (LIDT) and good spectral performance, which can be used as the enabling components for thermal control in high-power laser cavities.
\end{abstract}

Although hydrophobic coatings have been well studied regarding their water repellency or moisture proof property $^{1-3}$, they are not applicable under cooling water conditions $^{4-9}$, where coatings are immersed in water over long periods of time. For waterproof coatings, Murahara has proposed a hard-water-resistant coating that can protect KDP from dissolving ${ }^{10}$. However, his approach was limited to the use of $\mathrm{SiO}_{2}$ single layers and failed to meet the requirement of multilayers in which both highand low-index materials are needed ${ }^{11,12}$. Although the microstructures of widely used optical coatings prepared using physical vapor deposition techniques have been extensively studied regarding stress, the refractive index, humidity-induced spectral shift and so on ${ }^{13-15}$, the correlation between the coating microstructure and waterproof property has not been specifically addressed. To

Correspondence: Zhanshan Wang (wangzs@tongji.edu.cn)

${ }^{1}$ MOE Key Laboratory of Advanced Micro-Structured Materials, Shanghai 200092, China

${ }^{2}$ Institute of Precision Optical Engineering, School of Physics Science and Engineering, Tongji University, Shanghai 200092, China

Full list of author information is available at the end of the article. meet the challenging requirement of waterproof cavity mirrors, the dependence of water resistance on the microstructure of single- and multilayers was studied first. On the basis of these results, microstructure and bandgap engineering were performed to synthesize nanocomposite-based cavity mirrors with exceptional multifunctionality, which has been previously unattainable. The proposed multifunctional coating can be used as an enabling technology to realize high-repetition-rate laser inertial confinement fusion, which can then be used as a fusion power plant.

The schematic of a water-cooled Nd:Glass laser cavity is shown in Fig. 1. $\mathrm{SiO}_{2}$ and $\mathrm{HfO}_{2}$ are the dominant low and high index materials for the near-infrared region ${ }^{16,17}$. The water resistance of single layers was investigated first. $\mathrm{SiO}_{2}$ and $\mathrm{HfO}_{2}$ single layers were prepared using electron beam evaporation (EBE) and ion assisted deposition (IAD) processes, respectively. The coatings prepared by the EBE process had a porous microstructure and failed to protect $\mathrm{Nd}$ :Glass from water erosion. The $\mathrm{SiO}_{2}$ layers peeled off of $\mathrm{Nd}$ :Glass substrates with heating in a water bath over a period of several hours. The eroded morphologies of the

\section{(c) The Author(s) 2019}

(c) Open Access This article is licensed under a Creative Commons Attribution 4.0 International License, which permits use, sharing, adaptation, distribution and reproduction cc) in any medium or format, as long as you give appropriate credit to the original author(s) and the source, provide a link to the Creative Commons license, and indicate if changes were made. The images or other third party material in this article are included in the article's Creative Commons license, unless indicated otherwise in a credit line to the material. If material is not included in the article's Creative Commons license and your intended use is not permitted by statutory regulation or exceeds the permitted use, you will need to obtain permission directly from the copyright holder. To view a copy of this license, visit http://creativecommons.org/licenses/by/4.0/. 
$\mathrm{SiO}_{2}$ layer were recorded using a camera and an optical microscope, as shown in Fig. 2a1, a2. A cross-sectional transmission electron microscopy (TEM) image of a $\mathrm{Ta}_{2} \mathrm{O}_{5}$ coating was used instead to reveal the microstructure of the $\mathrm{SiO}_{2}$ coating, where the brighter areas

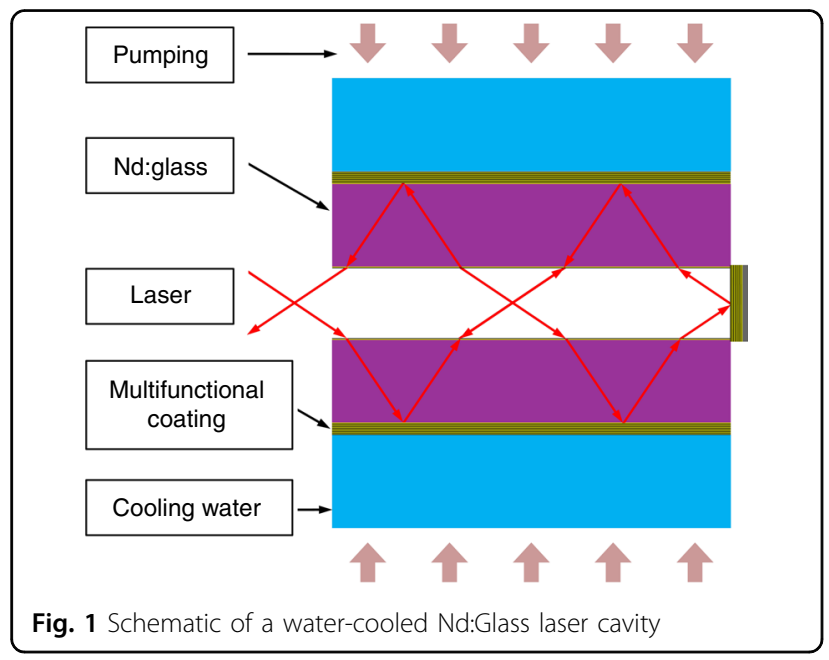

represent pores. It can be seen that an abundance of pores exist between the columns, which are open, elongated, and oriented perpendicular to the coating surface, as shown in Fig. 2a3. Water can quickly penetrate into the $\mathrm{Nd}$ :Glass surface through these open microscopic channels by capillarity, which is schematically illustrated in Fig. 2a4. Erosion of the Nd:Glass surface led to the delamination of $\mathrm{SiO}_{2}$ coatings. For porous $\mathrm{HfO}_{2}$ layers on $\mathrm{Nd}$ : Glass substrates, visible damage was observed after testing the samples in a hot water bath for several days, as shown in Fig. 2b1, b2. The relatively longer survival time of these layers is attributed to their different microstructure and pore characteristics. Figure $2 \mathrm{~b} 3$ shows that there is a transition from an amorphous microstructure to a polycrystalline microstructure as the coating grows thicker. Compared to the elongated pores in the amorphous coatings, the polycrystalline microstructure in the upper part of the $\mathrm{HfO}_{2}$ coating results in a substantially lower number of long and open pores. Water diffusion through the $\mathrm{HfO}_{2}$ layer is delayed due to these crisscrossing channels, which are illustrated in Fig. 2b4. This comparison shows that for porous coatings, the polycrystalline

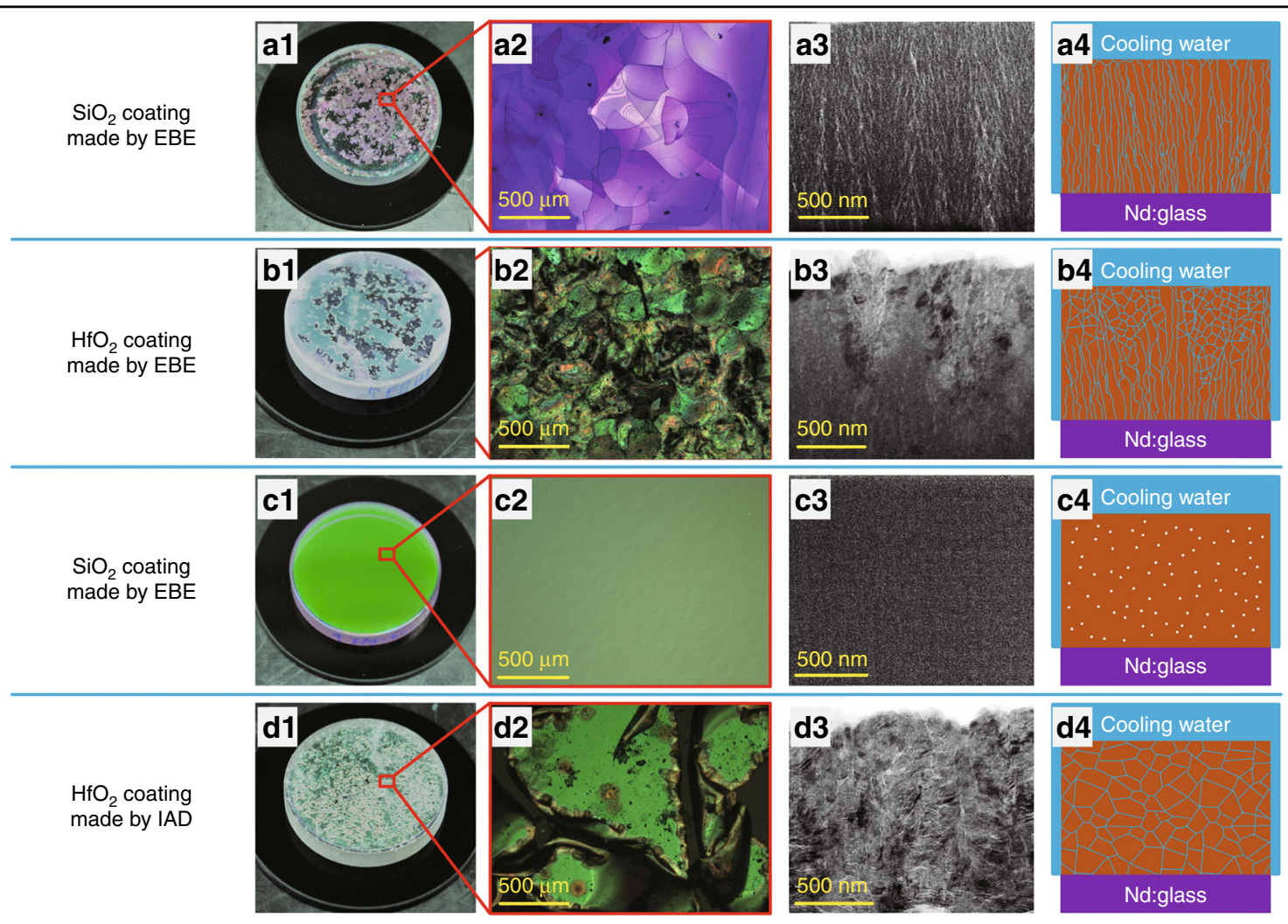

Fig. $2 \mathrm{SiO}_{2}$ and $\mathrm{HfO}_{2}$ coatings prepared by EBE and IAD processes. a1-d1 Optical photographs, a2-d2 microscopic images, a3-d3 crosssectional TEM images, a4-d4 schematics of water diffusion along the nanopores in the coatings. It is worth noting that the TEM images of the $\mathrm{SiO}_{2}$ coatings are replaced using TEM images of $\mathrm{Ta}_{2} \mathrm{O}_{5}$ coatings to better reveal the microstructure. TEM images and the electron diffraction pattern of the $\mathrm{SiO}_{2}$ coatings are shown in Figure $\mathrm{S} 2$ and $\mathrm{S} 3$ in the Supplementary Information 


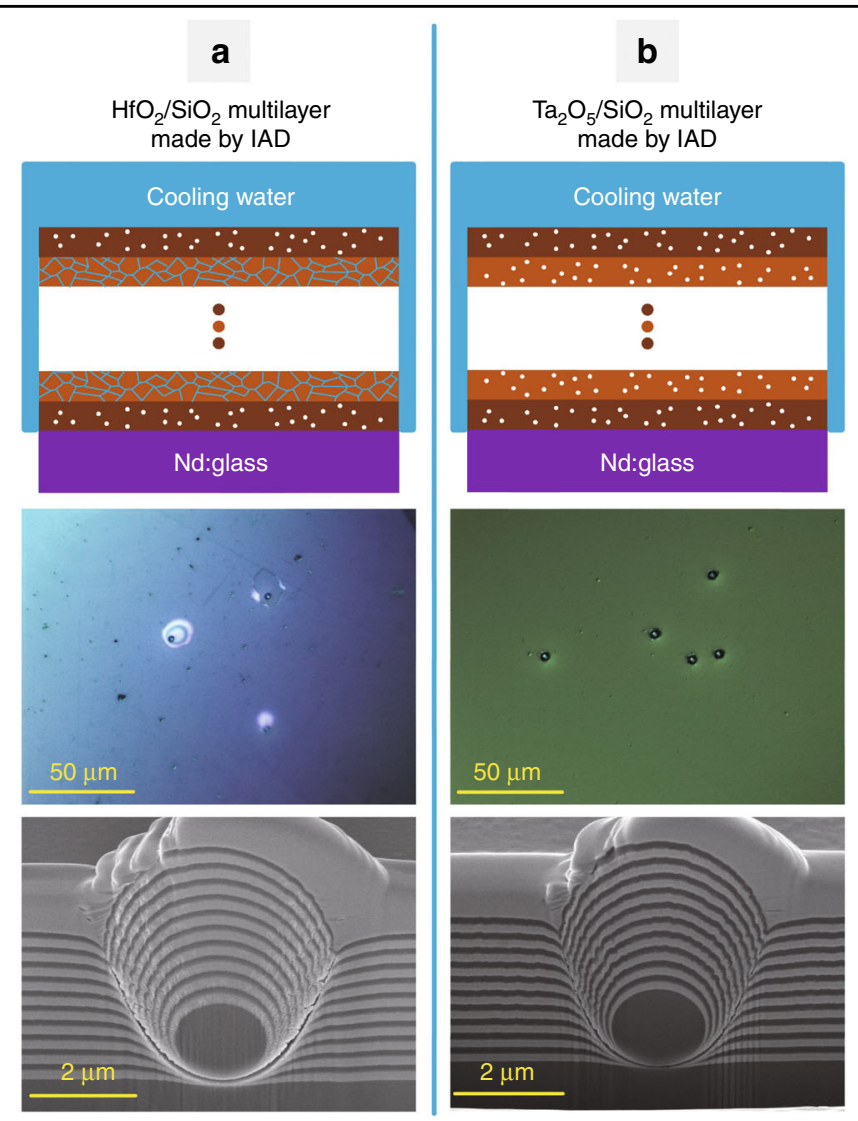

Fig. 3 Schematic of water diffusion in nanopores; optical photographs; cross-sectional SEM images of $\mathrm{HfO}_{2} / \mathrm{SiO}_{2}$ and $\mathrm{Ta}_{2} \mathrm{O}_{5} / \mathrm{SiO}_{2}$ multilayers prepared by an IAD process

microstructure offers advantages with respect to water resistant compared to an amorphous microstructure.

IAD can significantly reduce the number of pores in coatings via energetic ion bombardment during film growth. The densified $\mathrm{SiO}_{2}$ layers did not peel off of $\mathrm{Nd}$ : Glass substrates with water bath heating for several months, as shown in Fig. 2c1, c2. Although no visible pores can be identified in the cross-sectional TEM image in Fig. 2c3, some nanometer-sized closed pores are assumed to be embedded in the $\mathrm{SiO}_{2}$ coatings ${ }^{18}$. These closed nanopores are isolated from each other, as schematically presented in Fig. 2c4. There are no channels for water diffusion in dense amorphous $\mathrm{SiO}_{2}$ coatings, so $\mathrm{Nd}$ : Glass substrates can be protected from corrosion. $\mathrm{HfO}_{2}$ coatings prepared by the IAD process exhibited a polycrystalline microstructure. Although these coatings were also very dense, they failed to protect $\mathrm{Nd}$ :Glass from water erosion. Figure $2 \mathrm{~d} 1, \mathrm{~d} 2$ shows that $\mathrm{HfO}_{2}$ coatings were severely damaged after immersion in a hot water bath for several weeks. The cross-sectional TEM image shown in Fig. $2 \mathrm{~d} 3$ shows an abundance of complex grain boundaries with nanopores. These nanopores are connected with each other, resulting in a network of zigzag channels from which water can find ways to reach and erode the $\mathrm{Nd}$ : Glass, as shown in Fig. 2d4. This comparison reveals that for dense single layers, an amorphous microstructure rather than a crystallized microstructure exhibits a good waterproof property.

The water resistance of multilayers was further studied. $\mathrm{HfO}_{2} / \mathrm{SiO}_{2}$ multilayers were prepared using the IAD process. After immersing samples in a hot water bath for several months, severe delamination was observed. The erosion morphologies of $\mathrm{HfO}_{2} / \mathrm{SiO}_{2}$ multilayers are shown in Figure S1 in the Supplementary Information. This result means that a multilayer does not possess a good waterproof property when one coating material is water resistant while another is not. Although water penetration perpendicular to the surface might be effectively blocked by dense amorphous $\mathrm{SiO}_{2}$ layers, water can diffuse along zigzag channels in $\mathrm{HfO}_{2}$ layers that are parallel to the surface, as illustrated in Fig. 3a1. Since there are always extrinsic defects in real multilayer coatings ${ }^{19}$, water molecules in $\mathrm{HfO}_{2}$ layers could reach and corrode the Nd:Glass substrate along defectinduced channels, which could be linked to the Nd:Glass surface. 


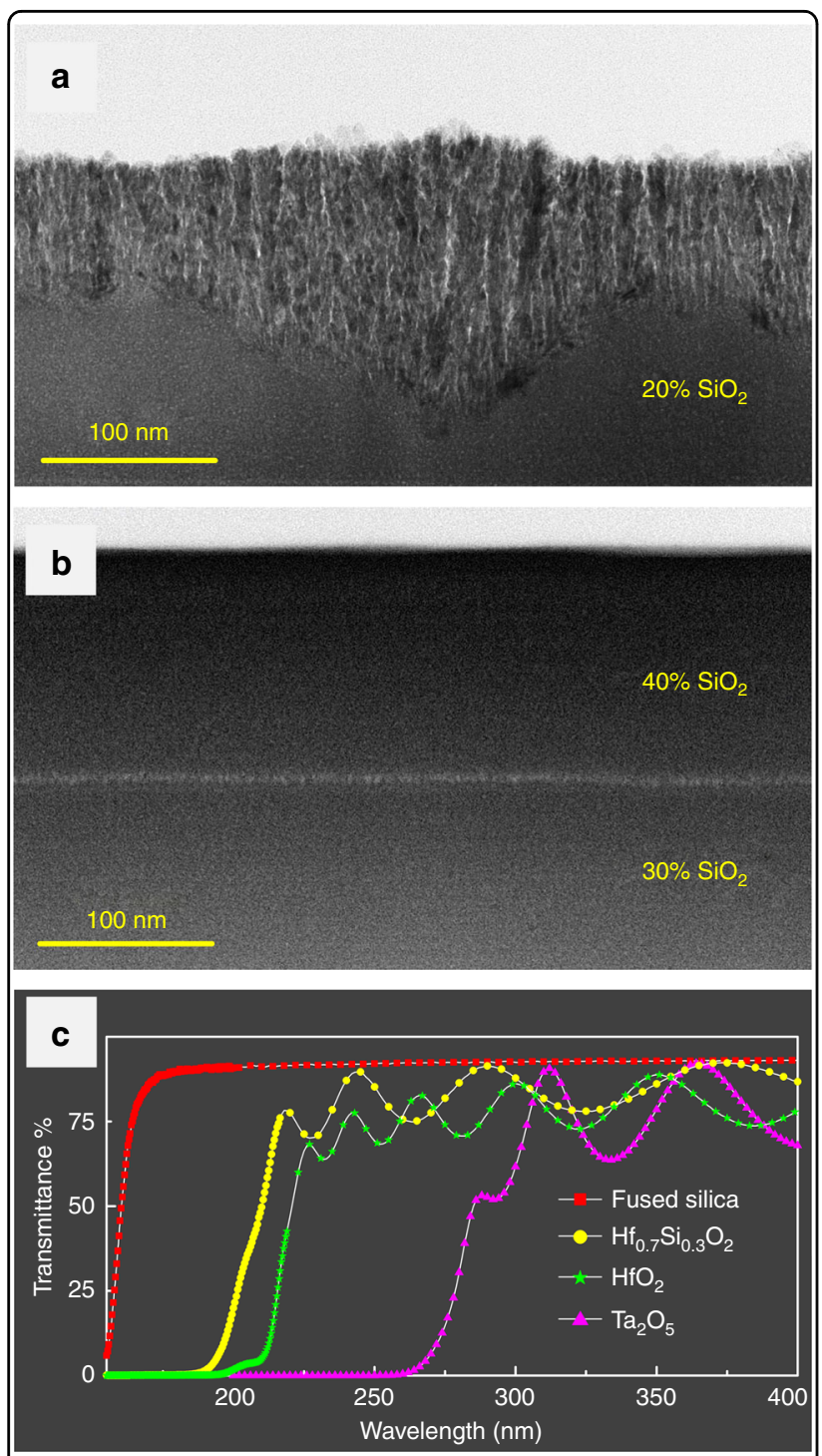

Fig. 4 Comparisons among $\mathrm{Hf}_{x} \mathrm{Si}_{1-x} \mathrm{O}_{2}$ nanocomposite films and oxide films. Cross-sectional TEM images of $\mathrm{Hf}_{x} \mathrm{Si}_{1}{ }_{-x} \mathrm{O}_{2}$ nanocomposite layers with a $20 \% \mathrm{SiO}_{2}$ concentration, b 30 and $40 \% \mathrm{SiO}_{2}$ concentration. c Transmission spectra of single layers of $\mathrm{Hf}_{0.7} \mathrm{Si}_{0.3} \mathrm{O}_{2}$, $\mathrm{SiO}_{2}, \mathrm{HfO}_{2}$ and $\mathrm{Ta}_{2} \mathrm{O}_{5}$

To verify the influence of defects, artificial nodules created from $2 \mu \mathrm{m}$ silica microspheres on Nd:Glass were tested in a hot water bath ${ }^{20}$. Figure $3 \mathrm{a} 2$ shows that blisters were observed at artificial nodules after serval hours of water bath heating. The cross-sectional scanning electron microscopy (SEM) image shown in Fig. 3a3 shows that large pores at nodular boundaries are open to the $\mathrm{Nd}$ : Glass surface, through which water can reach and erode the Nd:Glass. For comparison, artificial nodules in dense amorphous $\mathrm{Ta}_{2} \mathrm{O}_{5} / \mathrm{SiO}_{2}$ multilayers were also prepared using the IAD process. Because both $\mathrm{Ta}_{2} \mathrm{O}_{5}$ and $\mathrm{SiO}_{2}$ have a dense amorphous microstructure with closed nanopores, there are no channels for water diffusion along defect-induced channels, as shown in Fig. 3b. The $\mathrm{Ta}_{2} \mathrm{O}_{5} /$ $\mathrm{SiO}_{2}$ multilayers did not peel off from the Nd:Glass substrate for the same water bath time. However, the LIDT for the $\mathrm{Ta}_{2} \mathrm{O}_{5} / \mathrm{SiO}_{2}$ multilayers is much lower than that for the $\mathrm{HfO}_{2} / \mathrm{SiO}_{2}$ multilayers because the bandgap of $\mathrm{Ta}_{2} \mathrm{O}_{5}$ is $\sim 30 \%$ less than that of $\mathrm{HfO}_{2}{ }^{21}$. It is desirable to find novel coating materials to achieve an excellent waterproof property without sacrificing the LIDT.

Nanocomposites that dope $\mathrm{SiO}_{2}$ into $\mathrm{HfO}_{2}$ were synthesized using an ion-assisted co-evaporation process to obtain a dense amorphous microstructure, wider bandgap and higher LIDT. The higher the $\mathrm{SiO}_{2}$ concentration in $\mathrm{Hf}_{x} \mathrm{Si}_{1-x} \mathrm{O}_{2}$ nanocomposites, the better the resistance to crystallization. $\mathrm{SiO}_{2}(20 \%)$ in $\mathrm{Hf}_{x} \mathrm{Si}_{1-x} \mathrm{O}_{2}$ nanocomposites was not enough to suppress crystallization. Figure 4a shows that severe crystallization occurred after an initial amorphous growth phase. $\mathrm{Hf}_{x} \mathrm{Si}_{1-x} \mathrm{O}_{2}$ nanocomposites with a $30 \% \mathrm{SiO}_{2}$ concentration or higher maintained a dense amorphous microstructure, as shown in Fig. $4 \mathrm{~b}$. From the aspects of coating design and electric-field control, it is optimal to use an amorphous $\mathrm{Hf}_{x} \mathrm{Si}_{1-x} \mathrm{O}_{2}$ nanocomposite, which has the highest refractive index. Therefore, an $\mathrm{Hf}_{0.7} \mathrm{Si}_{0.3} \mathrm{O}_{2}$ nanocomposite layer was used. The ultraviolet transmission spectra of the $\mathrm{Hf}_{0.7} \mathrm{Si}_{0.3} \mathrm{O}_{2}$, $\mathrm{SiO}_{2}, \mathrm{HfO}_{2}$ and $\mathrm{Ta}_{2} \mathrm{O}_{5}$ layers are compared in Fig. 4c. Together with the reflection spectrum, the bandgap of the $\mathrm{Hf}_{0.7} \mathrm{Si}_{0.3} \mathrm{O}_{2}$ nanocomposite layer was derived to be $6.4 \mathrm{eV}$ using the Tauc algorithm ${ }^{22}$. The bandgap of this is much wider than that $\mathrm{Ta}_{2} \mathrm{O}_{5}$ and its LIDT should also be much higher.

$\mathrm{Hf}_{0.7} \mathrm{Si}_{0.3} \mathrm{O}_{2} / \mathrm{SiO}_{2}$ cavity mirrors were then prepared with a high reflectance at $1053 \mathrm{~nm}$ for s-polarization at the Brewster angle and a high transmittance at $802 \mathrm{~nm}$ for normal incidence ${ }^{23}$. Their LIDT was $34 \pm 4 \mathrm{~J} / \mathrm{cm}^{2}$ according to the method described by Borden et al. ${ }^{24}$, which is almost three times higher than the LIDT of $\mathrm{Ta}_{2} \mathrm{O}_{5} / \mathrm{SiO}_{2}$ cavity mirrors. This value is close to the LIDT value of $\sim 42 \pm 4 \mathrm{~J} / \mathrm{cm}^{2}$ for a bare Nd:Glass substrate. By carefully controlling defects during the preparation of $\mathrm{Nd}$ : Glass substrates and coatings, $\mathrm{Hf}_{0.7} \mathrm{Si}_{0.3} \mathrm{O}_{2} / \mathrm{SiO}_{2}$ cavity mirrors can protect Nd:Glass from corrosion for over 1 year, even in a hot water bath.

Here, the influence of the pore characteristics on the waterproof property of single layers was determined. Dense amorphous coatings are water resistant because no channels exist for water diffusion. If one material is water resistant while another is not, the multilayer does not possess a waterproof property when extrinsic defects are present. $\mathrm{Hf}_{x} \mathrm{Si}_{1-x} \mathrm{O}_{2}$ nanocomposites were then synthesized to generate $\mathrm{Hf}_{0.3} \mathrm{Si}_{0.7} \mathrm{O}_{2} / \mathrm{SiO}_{2}$ cavity mirrors with the multifunctionality of an excellent waterproof property, high LIDT and good spectral performance. 


\section{Materials and methods}

\section{Preparation of laser coatings}

$\mathrm{SiO}_{2}, \mathrm{HfO}_{2}$ and $\mathrm{Ta}_{2} \mathrm{O}_{5}$ single layers with a thickness of $\sim 500 \mathrm{~nm}$ were deposited on $\mathrm{Nd}$ :Glass substrates using $\mathrm{EBE}$ and IAD processes. The deposition temperature was approximately $393 \mathrm{~K}$, and the chamber was pumped down to a base pressure of $2.3 \times 10^{-4} \mathrm{~Pa}$. The IAD process employed was based on an RF-type ion source with a working condition of $600 \mathrm{~V}$ and $600 \mathrm{~mA}$. Further details of the deposition process can be found in our previous paper $^{25} . \mathrm{Hf}_{x} \mathrm{Si}_{1-x} \mathrm{O}_{2}$ nanocomposites were prepared using an ion-assisted co-evaporation process including annealing at $600{ }^{\circ} \mathrm{C}$ to reduce their absorption. A schematic of the ion-assisted co-evaporation process is shown in Figure S4 in the Supplementary Information. Further details of the process can be found in a previous paper ${ }^{26}$.

\section{Characterization of laser coatings}

The water resistance of the prepared coatings was evaluated by immersing samples in a temperaturecontrolled water bath. Compared to a practical watercooling situation, the temperature of the water bath was set to $90^{\circ} \mathrm{C}$ to accelerate the failure process.

The microstructure of $\mathrm{SiO}_{2}, \mathrm{HfO}_{2}$ and $\mathrm{Ta}_{2} \mathrm{O}_{5}$ single layers was characterized using TEM. However, due to the low contrast of electron scattering between pores and the $\mathrm{SiO}_{2}$ matrix, it is difficult to clearly observe its microstructure. Based on the fact that the $\mathrm{SiO}_{2}$ coating has the same microstructure as a $\mathrm{Ta}_{2} \mathrm{O}_{5}$ coating ${ }^{27}$, a crosssectional TEM image of a $\mathrm{Ta}_{2} \mathrm{O}_{5}$ coating was used instead to determine the microstructure of the $\mathrm{SiO}_{2}$ coating. For comparison, TEM images and electron diffraction patterns of $\mathrm{SiO}_{2}$ coatings are shown in Figures S2 and S3 in the Supplementary Information. The electron diffraction pattern of the crystallized part of the $\mathrm{HfO}_{2}$ coating is also shown in Figure S2 in the Supplementary Information. The microstructure of the artificial nodules in the $\mathrm{HfO}_{2} / \mathrm{SiO}_{2}$ and $\mathrm{Ta}_{2} \mathrm{O}_{5} / \mathrm{SiO}_{2}$ multilayers was determined by cutting them through the middle using focused ion beam technology. Then, the cross-sectional images shown in Fig. 3 were taken using SEM.

The concentration of $\mathrm{SiO}_{2}$ in $\mathrm{Hf}_{x} \mathrm{Si}_{1-x} \mathrm{O}_{2}$ nanocomposites was determined by fitting the refractive indices of the $\mathrm{Hf}_{x} \mathrm{Si}_{1-x} \mathrm{O}_{2}$ single layers using a Lorentz-Lorentz model $^{28}$.

\footnotetext{
Acknowledgements

This work was supported by the National Natural Science Foundation of China (Nos. 61522506, 51475335, 61621001 and 91536111), Joint Sino-German Research Project (No. GZ1275), National Program on Key Research Project (No. 2016YFA0200900), Major projects of Science and Technology Commission of Shanghai (No. 17JC1400800), "Shu Guang" project supported by Shanghai Municipal Education Commission and Shanghai Education (No. 17SG22), Development Foundation National Key Scientific Instrument and Equipment Development Project (No. 2014YQ090709).
}

\begin{abstract}
Author details
${ }^{1}$ MOE Key Laboratory of Advanced Micro-Structured Materials, Shanghai 200092, China. ${ }^{2}$ Institute of Precision Optical Engineering, School of Physics Science and Engineering, Tongji University, Shanghai 200092, China. ${ }^{3}$ IFSA Collaborative Innovation Center, Shanghai Jiao Tong University, Shanghai 200240, China. ${ }^{4}$ Laser Zentrum Hannover e.V., Laser Components Department, Hannover 30419, Germany
\end{abstract}

\section{Conflict of interest}

The authors declare that they have no conflict of interest.

Supplementary information is available for this paper at https://doi.org/ 10.1038/s41377-018-0118-6.

Received: 19 November 2018 Revised: 9 December 2018 Accepted: 17 December 2018

Published online: 23 January 2019

\section{References}

1. Voïtchovsky, K., Giofrè, D., Segura, J. J., Stellacci, F. \& Ceriotti, M. Thermallynucleated self-assembly of water and alcohol into stable structures at hydrophobic interfaces. Nat. Commun. 7, 13064 (2016).

2. Liu, K. C. et al. A flexible and superhydrophobic upconversion- luminescence membrane as an ultrasensitive fluorescence sensor for single droplet detection. Light Sci. Appl. 5, e16136 (2016).

3. Lee, H., Alcaraz, M. L., Rubner, M. F. \& Cohen, R. E. Zwitter- wettability and antifogging coatings with frost- resisting capabilities. ACS Nano 7, 2172-2185 (2013).

4. Jauregui, C., Limpert, J. \& Tünnermann, A. High-power fibre lasers. Nat. Photonics 7, 861-867 (2013).

5. Fan, Z. W. et al. High beam quality $5 \mathrm{~J}, 200 \mathrm{~Hz} \mathrm{Nd:YAG} \mathrm{laser} \mathrm{system.} \mathrm{Light} \mathrm{Sci.}$ Appl. 6, e17004 (2017)

6. Tauer, J., Kofler, H. \& Wintner, E. Laser-initiated ignition. Laser Photonics Rev. 4, 99-122 (2010).

7. Weber, R., Neuenschwander, B., Mac Donald, M., Roos, M. B. \& Weber, H. P. Cooling schemes for longitudinally diode laser-pumped Nd:YAG rods. IEEE J. Quantum Electron 34, 1046-1053 (1998).

8. Waldburger, D. et al. High-power 100 fs semiconductor disk lasers. Optica 3, 844-852 (2016).

9. Tokita, S., Murakami, M., Shimizu, S., Hashida, M. \& Sakabe, S. Liquid-cooled 24 W mid-infrared Er:ZBLAN fiber laser. Opt. Lett. 34, 3062-3064 (2009).

10. Murahara, M., Sato, N. \& Ikadai, A. Hard protective waterproof coating for highpower laser optical elements. Opt. Lett. 30, 3416-3418 (2005)

11. Jung, B. H., Lee, D. K., Sohn, S. H. \& Kim, H. S. Thermal, dielectric, and optical properties of neodymium borosilicate glasses for thick films. J. Am. Ceram. Soc. 86, 1202-1204 (2003)

12. Šuminas, R., Tamošauskas, G., Valiulis, G. \& Dubietis, A. Spatiotemporal light bullets and supercontinuum generation in $\beta-B B O$ crystal with competing quadratic and cubic nonlinearities. Opt. Lett. 41, 2097-2100 (2016).

13. Vinnichenko, $\mathrm{M}$. et al. Highly dense amorphous $\mathrm{Nb}_{2} \mathrm{O}_{5}$ films with closed nanosized pores. Appl. Phys. Lett. 95, 081904 (2009).

14. Tolenis, T. et al. Next generation highly resistant mirrors featuring all-silica layers. Sci. Rep. 7, 10898 (2017).

15. Lupoi, R. et al. Hardfacing steel with nanostructured coatings of Stellite- 6 by supersonic laser deposition. Light Sci. Appl. 1, e10 (2012).

16. Wang, A. Q. et al. $\mathrm{HfO}_{2} / \mathrm{SiO}_{2}$ multilayer enhanced aluminum alloy-based dualwavelength high reflective optics. Thin. Solid. Films. 592, 232-236 (2015).

17. Cheng, X. B. et al. The effect of an electric field on the thermomechanical damage of nodular defects in dielectric multilayer coatings irradiated by nanosecond laser pulses. Light Sci. Appl. 2, e80 (2013).

18. Stenzel, O. A model for calculating the effect of nanosized pores on refractive index, thermal shift and mechanical stress in optical coatings. J. Phys. D Appl. Phys. 42, 055312 (2009).

19. Stolz, C. J. et al. Substrate and coating defect planarization strategies for highlaser-fluence multilayer mirrors. Thin. Solid. Films. 592, 216-220 (2015).

20. Cheng, X. B. et al. Contribution of angle-dependent light penetration to electric-field enhancement at nodules in optical coatings. Opt. Lett. 42, 2086-2089 (2017) 
21. Jensen, L., Mende, M., Schrameyer, S., Jupé, M. \& Ristau, D. Role of two-photon absorption in $\mathrm{Ta}_{2} \mathrm{O}_{5}$ thin films in nanosecond laser-induced damage. Opt. Lett. 37, 4329-4331 (2012).

22. Cody, G. D., Tiedje, T., Abeles, B., Brooks, B. \& Goldstein, Y. Disorder and the optical-absorption edge of hydrogenated amorphous silicon. Phys. Rev. Lett. 47, 1480-1483 (1981).

23. Cheng, X. B. et al. Optimal coating solution for a compact resonating cavity working at Brewster angle. Opt. Express 24, 24313-24320 (2016).

24. Borden, M. R., et al. Improved method for laser damage testing coated optics. In Proceedings of SPIE 5991, Laser-Induced Damage in Optical Materials. p59912A (SPIE, Boulder, 2006).
25. Wang, Z. S. et al. Interfacial damage in a $\mathrm{Ta}_{2} \mathrm{O}_{5} / \mathrm{SiO}_{2}$ double cavity filter irradiated by $1064 \mathrm{~nm}$ nanosecond laser pulses. Opt. Express 21, 30623-30632 (2013).

26. Liu, F. et al. Interface and material engineering for zigzag slab lasers. Sci. Rep. 7 16699 (2017).

27. Kaiser, N. Review of the fundamentals of thin-film growth. Appl. Opt. 41, 3053-3060 (2002)

28. Cheng, X. B., Fan, B., Haruo, T. \& Wang Z. S. Optical and structural properties of $\mathrm{Nb}_{x} \mathrm{Si}_{y} \mathrm{O}$ composite films prepared by metallic co-sputtering process. In Proceedings Volume 7101, Advances in Optical Thin Films III. p71011G (SPIE, Glasgow, 2008). 